\title{
PENGARUH KOMPOSISI CAMPURAN HARDENER DENGAN RESIN POLYESTER TERHADAP KUAT TARIK DAN BENDING POLIMER TERMOSET
}

\author{
La Maaliku', Yuspian Gunawan², Aminur ${ }^{2}$ \\ ${ }^{1}$ Mahasiswa Program Studi Teknik Mesin Fakultas Teknik Universitas Halu Oleo, Kendari \\ ${ }^{2}$ Staf Pengajar Program Studi Teknik Mesin Fakultas Teknik Universitas Halu Oleo, Kendari \\ E-mail : lamaaliku_xvb@yahoo.co.id
}

\begin{abstract}
Abstrak
Tujuan dalam penelitian ini adalah untuk mengetahui komposisi campuran yang ideal dalam proses pembuatan polyester pada polimer termoset, dimana komposisi campuran ini akan memiliki kekuatan tarik dan kekuatan bending yang tinggi. Polimer termoset ini dibuat dengan mencampurkan resin polyester dengan dengan hardener, bervariasi antara $1 \%, 3 \%, 5 \%, 7 \%$, dan $9 \%$. Resin polyester yang telah dicampur dengan hardener dituang ke dalam cetakan. Setelah mengering, polimer ini dimasukan ke dalam oven untuk dipanaskan sampai suhu $80^{\circ} \mathrm{C}$. Setelah dingin kembali, dibuat spesimen uji tarik dan uji bending. Pengujian tarik dilakukan dengan menggunakan standar ASTM D 638-02 tipe 4, dan pengujian bending dilakukan dangan standar ASTM D709-02 tipe 4. Dari hasil pengujian kekuatan tarik dan kekuatan bending diperoleh kekuatan maksimum yang terdapat pada komposisi campuran 99\%:1\% dengan nilai masing-masing sebesar $57,43 \mathrm{~N} / \mathrm{mm}^{2}$ dan $91,826 \mathrm{~N} / \mathrm{mm}^{2}$.
\end{abstract}

Kata kunci: hardener, resin, kekuatan tarik, bending, polimer

\begin{abstract}
The effect on the composition on the mixing of hardener and resin to the tensile and bending strength of a thermoset polymer. The objective of this research is to determine the ideal mixing composition on the process of making polyester in thermoset polymer, at which the composition has the high tensile strength and the high bending strength. The thermoset polymer is made by mixing the polyester resin with the hardener by the variation of $1 \%, 3 \%$, $5 \%, 7 \%$, and $9 \%$. The mixed hardener polyester resin is poured into a mold. Once dried, it is inserted into an oven to be heated to the temperature of $80^{\circ} \mathrm{C}$. After in cooling condition, a test specimen is conducted, for the tensile and bending tests. It uses the standard of ASTM D 638-02 type 4 for the tensile test and that of ASTM D709-02 type 4 for the bending test. From the results on both tensile and bending tests, the maximum strength is obtained by the composition with the mixture $99 \%: 1 \%$, accounting for $57,43 \mathrm{~N} / \mathrm{mm} 2$ and $91,826 \mathrm{~N} / \mathrm{mm}^{2}$ respectively.
\end{abstract}

Keywords: hardener, resin, tensile, bending, polymer

\section{Pendahuluan}

Polyester merupakan bahan yang sangat bermanfaat dalam dunia teknik, khususnya dalam industri kontruksi. Dalam konstruksi berbagai jenis kendaraan bermotor sering menggunakan polyester sebagai bahan bakunya. Sifat fisik dan kimia dari polyester sangat berkaitan erat dengan identifikasi penanganan dan pencampuran aplikasi dari polyester itu sendiri (Rikson dkk, 2008).
Polyester merupakan jenis resin thermoset. Polyester memiliki sifat encer dan fluiditasnya baik sehingga dapat diaplikasikan mulai dari proses hand lay up yang sederhana sampai dengan proses yang kompleks. Banyaknya penggunaan resin ini didasarkan pada pertimbangan harga yang murah, curing yang cepat, warna yang jernih, dan mudah penanganannya. Katalis yang sering digunakan sebagai media untuk mempercepat 
pengerasan cairan resin (curing) adalah Hardener Methyl Ethyl Ketone Peroxide (Wijayanti, 2012).

Bahan hardener merupakan bahan yang memungkinkan terjadinya proses curing. Hardener ini terdiri dari dua bahan, yaitu katalisator dan accelerator. Katalisator dan accelerator akan menimbulkan panas, dimana pengaruh panas ini diperlukan untuk mempercepat proses pengeringan sehingga bahan menjadi kuat. Namun apabila panasnya terlalu tinggi maka akan merusak ikatan-ikatan antar molekul dan juga akan merusak seratnya (Suharpiyu, 2000).

Manakala perbandingan komposisi campuran antara polyester dengan hardener terlalu rendah maka polimer yang dihasilkan akan memiliki sifat elastis, dan proses curing atau pengerasan dapat berlangsung lama. Sementara bila perbandingan komposisi campuran antara polyester dengan hardener terlalu besar maka proses curing akan berlangsung dengan cepat namun menghasilkan sifat getas pada polimer tersebut. Untuk memperoleh sifat mekanik polimer seperti yang diinginkan maka dibutuhkan komposisi campuran yang sesuai antara polyester dengan hardener (Suharpiyu, 2000).

Tujuan dalam penelitian ini adalah untuk mengetahui komposisi campuran yang ideal dalam proses pembuatan polyester, dimana komposisi campuran ini memiliki kekuatan tarik dan kekuatan bending yang tinggi.

\section{Tinjauan Pustaka}

\section{Polimer}

Polimer merupakan molekul besar yang terbentuk dari unit-unit berulang sederhana. Nama ini diturunkan dari bahasa Yunani yakni Poly, yang berarti banyak dan Mer, yang berarti bagian. Industri polimer (polimer sintesis) baru dikembangkan beberapa puluh tahun terakhir ini (Rikson,2008).

\section{Resin Polyester}

Polyester merupakan bahan termoseting yang banyak beredar di pasaran karena harganya yang relatif murah dan dapat diaplikasikan untuk berbagai macam penggunaan. Istilah polyester berawal dari reaksi antara asam organik dengan alkohol yang membentuk suatu ester. Gambar 1 menunjukan sebuah pembentukan polyester dengan menggunakan dwi-fungsi asam dan dwifungsi alkohol (glikol).<smiles>[O]C(=O)PC(=O)O[Te]O</smiles>

Gambar 1. Reaksi pembentukan ester

(Sumber : Rikson, 2008 )

Polyester tidak jenuh dibagi ke dalam jenis yang tergantung pada struktur dasar blok. Kelas tersebut adalah ortoftalat, isophthalik, terephthalat, bisphenol-fumarat dan klorendik disiklopentadien. Sifat fisik dan kimia dari polyester sangat berkaitan dengan identifikasi penanganan dan pencampuran aplikasi dari polyester ini sendiri (Rikson,2008) ( Wati, 2009).

\section{Pengujian Kekuatan Tarik}

Pengujian tarik dilakukan dengan mesin uji tarik atau dengan Universal Testing Standar (standar ASTM D 638-02).

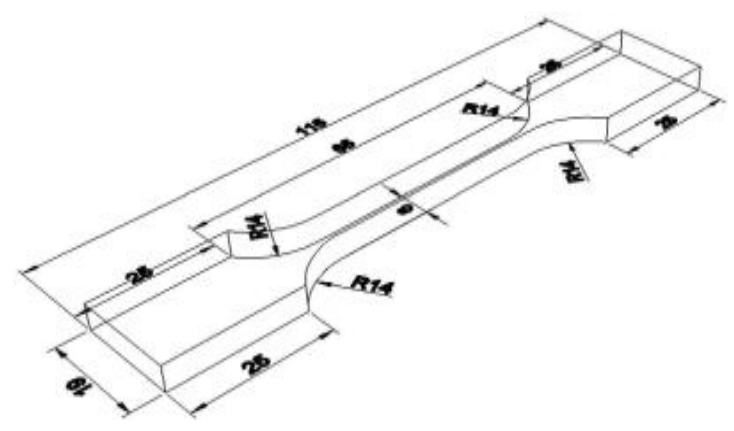

Gambar 2. Dimensi dan ukuran spesimen uji tarik (Sumber : Rabiul, 2013 )

Hubungan antara tegangan dan regangan pada beban tarik ditentukan dengan rumus sebagai berikut (Rabiul, 2013).

$\mathrm{F}=\sigma \cdot A$ atau $\sigma=\frac{\mathrm{F}}{A}$

Dimana :

$\mathrm{F}:$ Beban $(\mathrm{N})$

A : Luas penampang $\left(\mathrm{mm}^{2}\right)$

$\sigma$ : Tegangan $\left(\mathrm{N} / \mathrm{mm}^{2}\right)$ 


\section{DINAMIKA Jurnal Ilmiah Teknik Mesin}

\section{Pengujian Kekutan Bending}

Untuk menghitung kekuatan bending dapat menggunakan persamaan berikut (Simbolon, 2003) (Zahra, 2012).

$\sigma=\frac{3 F L}{2 \cdot b \cdot d^{2}}$

Dimana:

L : Panjang spesimen (mm)

B : Lebar (mm)

$\mathrm{d}$ : Tebal (mm)

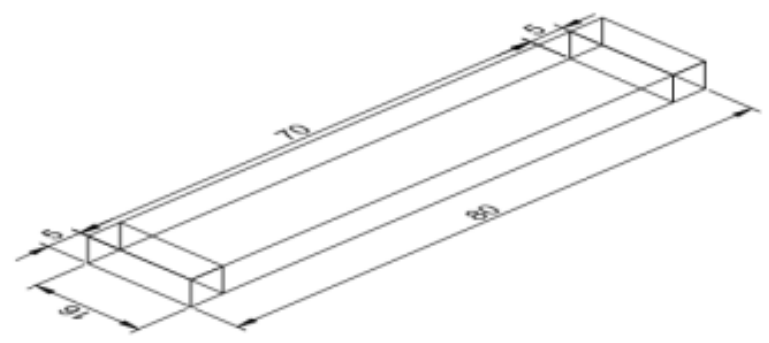

Gambar 3. Dimensi dan ukuran spesimen uji bending (Sumber : Simbolon, 2003 )

Untuk menentukan modulus elastisitas bending dapat digunakan rumus sebagai berikut (Standar ASTM D709-02).

$E=\frac{F L^{3}}{4 . b \cdot d^{3} \cdot \delta}$

Dimana,

E : Modulus bending $\left(\mathrm{N} / \mathrm{mm}^{2}\right)$

$\delta:$ Defleksi (mm)

\section{Metode Penelitian}

Langkah pertama yang dilakukan dalam penelitian ini adalah menyediakan resin polyester dan hardener. Setelah kedua bahan tersebut telah siap, selanjutnya menyediakan cetakan untuk membuat polimer serta timbangan untuk mengukur parbandingan capuran.

Langkah kedua adalah mengoleskan mirror glaze pada cetakan, dan selanjutnya mengukur perbandingan antara polyester dengan hardener menggunakan timbangan digital. Kosentrasi hardener yang digunakan pada campuran resin polyester adalah sebesar $1 \%, 3 \%, 5 \%, 7 \%$, dan $9 \%$.
Langkah selanjutnya adalah melakukan pencampuran antara hardener dan resin polyester dengan perbandingan yang telah ditentukan untuk kemudian dimasukan ke dalam cetakan. Setelah mengering, polimer yang ada dalam cetakan dikeluarkan untuk di-curing pada temperatur $80{ }^{\circ} \mathrm{C}$ selama 60 menit. Selanjutnya dilakukan proses pembuatan spesimen uji tarik dan spesimen uji bending untuk kemudian dilakukan proses pengujian.

\section{Hasil dan Pembahasan}

\section{Kekuatan Tarik pada Resin Polyester- Hardener Mekpo berdasarkan komposisi campuran}

Gambar 4 menunjukan tegangan tarik polimer termoset resin polyester-hardener mekpo berdasarkan komposisi campuran.

Dari gambar ini, terlihat bahwa pada komposisi campuran dengan komposisi resin sebesar $99 \%$ dan hardener mekpo sebesar $1 \%$ memiliki tegangan tarik maksimum sebesar $57,44 \mathrm{~N} / \mathrm{mm}^{2}$, dan pada campuran dengan komposisi resin sebesar $97 \%$ dan hardener mekpo sebesar $3 \%$ memiliki tegangan tarik maksimum sebesar 43,86 N/mm².

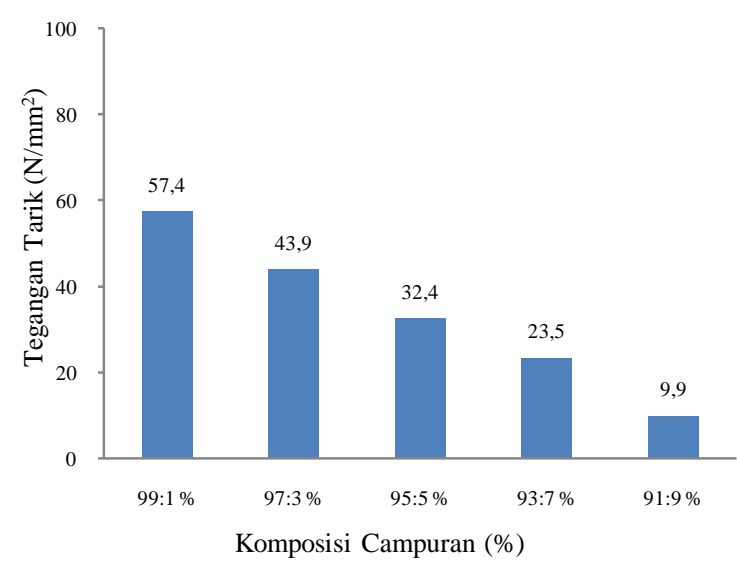

Gambar 4. Tegangan tarik dan komposisi campuran

Sementara pada campuran dengan komposisi resin sebesar $95 \%$ dan hardener mekpo sebesar 5\% tegangan tariknya menurun $\left(32,42 \mathrm{~N} / \mathrm{mm}^{2}\right)$. Pada komposisi campuran dengan kadar resin sebesar 97\% dan kadar hardener mekpo sebesar 3\%, dan pada komposisi campuran dengan kadar resin $91 \%$ dan kadar hardener sebesar $1 \%$ nilai tegangan tarik 
juga menurun, masing-masing nilai sebesar 23,46 $\mathrm{N} / \mathrm{mm}^{2}$ dan $9,89 \mathrm{~N} / \mathrm{mm}^{2}$.

Berdasarkan hasil ini dapat dikatakan bahwa semakin tinggi persentasi hardener pada campuran resin polyester, maka tegangan tariknya semakin menurun. Fenomena ini dipengaruhi oleh beberapa faktor, diantaranya adalah proses pencampuran yang kurang sempurna, karena proses curing yang berlangsung terlalu cepat sehingga mengakibatkan ketidak-sempuraan proses kimia yang terjadi.

Proses curing yang berlangsung terlalu cepat disebabkan karena terlalu banyaknya komposisi hardener pada proses pencapuran, sehingga menyebabkan panas yang berlebihan dan mengakibatkan ikatan-ikatan molekulnya rusak. Proses curing yang terlalu cepat juga mengakibatkan terjadinya void atau terjebaknya udara dalam cairan polimer.

\section{Kekuatan Bending pada Resin Polyester- Hardener Mekpo Berdasarkan Komposisi Campuran}

Gambar 5 menunjukan hubungan antara komposisi campuran resin polyester dan hardener mekpo dengan tegangan bending.

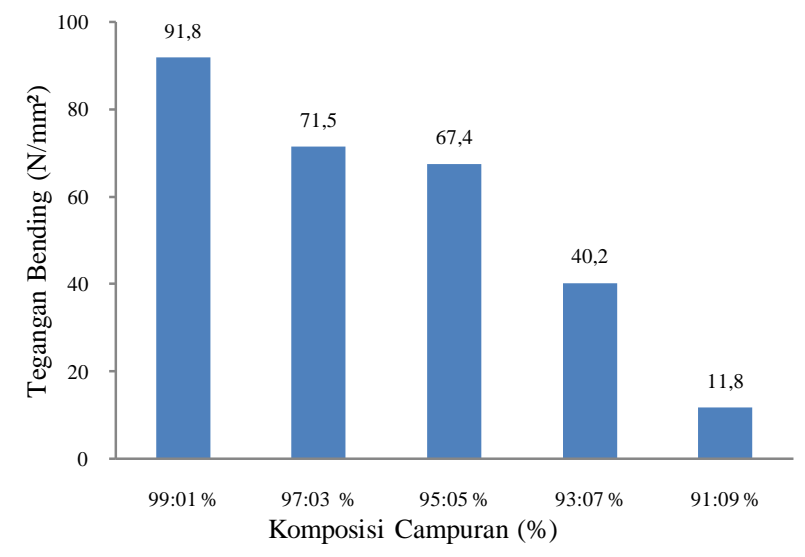

Gambar 5. Tegangan bending dan komposisi campuran

Nilai rata-rata tegangan bending tertinggi terdapat pada komposisi dengan perbandingan campuran antara resin polyester dan hardener mekpo yaitu 99\% : $1 \%$ dengan kisaran angka hingga 91,826 $\mathrm{N} / \mathrm{mm}^{2}$. Sementara pada komposisi dengan perbandingan campuran antara resin polyester dan hardener mekpo dengan perbandingan $97 \%$ : $3 \%$ nilai tegangan bending menurun, dengan nilai ratarata tegangan bending sebesar $71,473 \mathrm{~N} / \mathrm{mm}^{2}$.

Pada perbandingan campuran 95\%:5\% antara resin polyester dan hardener mekpo, nilai tegangannya terus mengalami penurunan $(67,436$ $\mathrm{N} / \mathrm{mm}^{2}$ ). Nilai rata-rata tegangan bending semakin menurun pada komposisi campuran dengan perbandingan 93\%:7\% dengan nilai rata-rata tegangan bending sebesar 40,215 N/mm². Nilai tegangan bending pada komposisi campuran 91\%:9\% menurun secara drastis hingga $(28,46$ $\mathrm{N} / \mathrm{mm}^{2}$ ).

Darihasil perbandingan komposisi campuran terhadap kuat tarik dan bending diatas, maka dapat ditentukan selisih nilai antara kekuatan tarik dan kekuatan bending dengan metode nilai dari kekuatan bending dikurangkan dengan nilai kekuatan tarik. Dari hasil penggunaan metode ini, pada komposisi campuran dengan perbandingan 99\%:1 \% menunjukan nilai selisih sebesar 34,39 $\mathrm{N} / \mathrm{mm}^{2}$, sementara pada komposisi campuran dengan perbandingan 97\%:3\% diperoleh selisih sebesar $27,63 \mathrm{~N} / \mathrm{mm}^{2}$. Sementara pada komposisi campuran dengan perbandingan 95\%:5\% menunjukan selisih nilai paling tinggi $(35,02$ $\mathrm{N} / \mathrm{mm}^{2}$ ), dan pada komposisi campuran dengan perbandingan 93:7 \% hanya memiliki nilai selisih sebesar $16,77 \mathrm{~N} / \mathrm{mm}^{2}$. Nilai selisih paling rendah terdapat pada komposisi campuran dengan perbandingan $91: 9 \%\left(1,86 \mathrm{~N} / \mathrm{mm}^{2}\right)$.

\section{Kesimpulan dan Saran}

Berdasarkan data hasil penelitian maka dapat ditarik kesimpulan bahwa komposisi campuran yang ideal, terdapat pada komposisi campuran yang memiliki nilai tinggi pada tegangan tarik dan tegangan bending yaitu pada campuran dengan perbandingan komposisi 99:1\% (nilai tegangan tarik sebesar $57,44 \mathrm{~N} / \mathrm{mm}^{2}$ dan tegangan bending sebesar 91,83 N/mm²).

Saran dalam penelitian ini adalah diperlukan pengujian komposisi kimia untuk mengetahui pengaruh perubahan reaksi kimia yang terjadi. Selain itu, sangat diperlukan penelitian lebih lanjut tentang perbandingan komposisi campuran antara resin polyester dan hardener mekpo pada perbandingan komposisi campuran yang lain. 


\section{Daftar Pustaka}

Rabiul SM. 2013, “Analisa Kekuatan Tarik Dan Densitas Komposit Polimer Berpenguat Serbuk Cangkang Telur". Fakultas Teknik Universitas Haluoleo Kendari ( Skripsi ).

Rikson AF, Siburian. 2008, "Polimer, Ilmu Material. Kupang”, Departemen Kimia Universitas Nusa Cendana

Simbolon TR. 2008, “Ilmu Material”. Departeman Fisika Universitas Suamatra Utara

Suharpiyu. 2000, "Pengaruh Komposisi Dan Beban Tekan Terhadap Karakteristik Rigid Bonded Magnet Berbasis Logam Tanah Jarang Nd-Fe-B Dengan Bahan Pengikat ResinPolyester".

Wati. 2009, "Imobilisasi Limbah Cair Transuranium Simulasi Dari Instalasi Radiometalurgi Dengan Polimer Polyester Tak Jenuh".

Wijayanti H. 2012, "Pengaruh Penambahan Serbuk Tembaga Dan Grafit Terhadap Sifat Mekanik Unsaturated Polyester". Universitas Indonesia

Zahra AF. 2012, "Pengaruh Penambahan 530WT\& Serbuk Tembaga Terhadap Sifat Mekanik Komposit Grafit-Unsaturated Polyester". 